\title{
Article \\ Research on On-Line Monitoring System of Hydraulic Actuator of Combine Harvester
}

\author{
Ruichuan $\mathrm{Li}^{1}$, Yi Cheng ${ }^{1}{ }^{1}$, Jikang $\mathrm{Xu}^{2, *}$, Yanchao $\mathrm{Li}^{3}{ }^{3}$, Xinkai Ding ${ }^{1}$ and Shan Zhao ${ }^{3}$ \\ 1 School of Mechanical and Automotive Engineering, Qilu University of Technology (Shandong Academy of \\ Sciences), Jinan 250353, China; liruichuan@qlu.edu.cn (R.L.); cy11075511@126.com (Y.C.); \\ dingxinkaihpu@163.com (X.D.) \\ 2 School of Transportation, Shandong University of Science and Technology, Qingdao 266590, China \\ 3 School of Mechanical and Electronic Engineering, Shandong University of Science and Technology, \\ Qingdao 266590, China; liyanchao199209@163.com (Y.L.); zs1234561214@163.com (S.Z.) \\ * Correspondence: 15275289164@163.com; Tel.: +86-15275289164
}

Citation: Li, R.; Cheng, Y.; Xu, J.; Li, Y.; Ding, X.; Zhao, S. Research on On-Line Monitoring System of Hydraulic Actuator of Combine Harvester. Processes 2022, 10, 35. https://doi.org/10.3390/pr10010035

Academic Editors:

Harvey Arellano-Garcia and

Philippe Bogaerts

Received: 7 November 2021

Accepted: 21 December 2021

Published: 24 December 2021

Publisher's Note: MDPI stays neutral with regard to jurisdictional claims in published maps and institutional affiliations.

Copyright: (c) 2021 by the authors. Licensee MDPI, Basel, Switzerland. This article is an open access article distributed under the terms and conditions of the Creative Commons Attribution (CC BY) license (https:// creativecommons.org/licenses/by/ $4.0 /)$.

\begin{abstract}
In view of the complicated hydraulic system, the many driving parts and the great load variation in the combine harvester, and on-line monitoring methods of hydraulic actuating parts such as cutting tables, conveyors and threshing drums were studied. By analyzing the working principle of the hydraulic system of the combine harvester, a mathematical model of the hydraulic system of the combine harvester was established; a simulation model for the fault diagnosis of the hydraulic system of the combine harvester was established based on AMESim. The load signal was introduced to simulate the feeding amount, and the simulation test was carried out. According to the simulation analysis results, the best position of each monitoring point was determined. The on-line monitoring system of the hydraulic actuators of the combine harvester was designed by using LabView, which can collect and display the working parameters of the main working parts of a combine harvester in real time, and alarm the user to faulty working conditions. The field experiment results show that the function and precision of the monitoring system completely meet the requirements of field operation condition monitoring of combine harvesters. The accuracy rate of the fault alarm is $96.5 \%$, and the automatic diagnosis time of the fault alarm is less than $1 \mathrm{~min}$ and $18 \mathrm{~s}$, which greatly improves the operation efficiency of the combine harvester.
\end{abstract}

Keywords: combine harvester; on-line monitoring; hydraulic actuating unit; fault alarm; the sensor

\section{Introduction}

The executing parts of the hydraulic system of the combine harvester are mainly composed of a cutting table, rotary wheel, conveyor and threshing drum. The working status of each part has a direct impact on the operating performance of the combine harvester [1-3]. However, the domestic harvester automation level is low, and as commonly occurs in the process of operation, the work efficiency is low. Most of the performance monitoring of combine harvesters in China adopts the form of single-parameter instrument monitoring, and the monitoring objects mainly include walking speed, engine working condition, feeding amount, etc. With low monitoring accuracy, the reliability of monitoring results is difficult to ensure, and the failure state of combine harvesters cannot be found in time [4].

Foreign combine harvester monitoring technology is relatively mature. The Green Star system developed by John Deere realizes the real-time on-line monitoring of the working speed, feeding amount, threshing rate and working status of working parts $[5,6]$. The AFS system developed by Case New Holland can monitor crop quality, threshing rate and grain moisture content in real time and form a yield graph $[7,8]$. The RDS system developed by Claas Company can realize real-time operation control of harvesters $[9,10]$. The Field Star system developed by Massey Ferguson can realize the remote monitoring of operational information and has a self-diagnosis function [11]. Our country's researchers have also 
carried out much research in the agricultural machinery monitoring of combine harvesters. In view of the problem that it is difficult for the driver to know the operation of components in a timely manner, and the poor real-time performance of agricultural machinery operation information during the operation of a combine harvester, Chen Jin and others designed and developed a video monitoring system suitable for the operation site of combine harvesters, which realizes the combination of airborne and remote monitoring [12]. Ren Huixia analyzed the application of automatic control in a combine harvester, demonstrated that the development trend in the automatic control of combine harvester is intelligent fuzzy control, and pointed out that at present, the automatic control of combine harvesters in China should take the road of combining centralized control and decentralized monitoring [13]. Due to the inconvenience of the single-monitoring method of combine operation processes, Zheng Shiyu uses microprocessors and LCD to realize the real-time display of combine operation status data. The test shows that the integration of combine operation process monitoring and control systems can be realized [14]. Aiming at the important influence of hydraulic system fault on the working state of the whole machine, Yang Yanxia and others designed a hydraulic system state detection system based on a virtual instrument, which can realize rapid detection and early fault warning [15]. With the progress of science and technology and the improvement in living standards, people's demand for the automation and intelligence of all machinery is becoming increasingly fierce, including agricultural machinery, especially combine harvesters. For farmers, the higher the automation and intelligence level of the combine harvester, the fewer failures during harvesting, the faster the harvesting speed and the higher the operation efficiency, which greatly reduces human labor and indirectly improves people's economic income. Coupled with the support of national policies, combine harvesters will integrate multi-source information collection and processing and rapid diagnosis technology for hidden trouble [16,17].

At present, the automation level of combine harvesters in China is still low, the operation process monitoring system is not perfect, the operation process is prone to failure and the work efficiency is low. In order to solve this problem, the main hydraulic actuator components affecting the efficient harvest of crops by the combine harvester are determined by reading the literature, learning courses and simulation analysis. In this paper, on-line monitoring and fault alarm methods for the cutting table, screw conveyor, conveyor trough and threshing drum of a combine harvester are studied. The on-line monitoring system for the hydraulic actuator of a combine harvester is designed by using multi-sensor monitoring technology and breaking through multi-source sensor data fusion. Real-time monitoring of the operation parameters of a combine harvester is provided for the driver to facilitate timely processing, reduce the occurrence of operation failures, and improve the work efficiency of combine harvesters [18-20].

\section{Experimental Methods}

\subsection{Mathematical Model of Hydraulic System}

The electro-hydraulic proportional valve is the main control valve of the hydraulic system of a combine harvester. The essence of an electro-hydraulic proportional valve is the combination between an electromagnet and reversing valve. The control signal output by the controller is driven by a proportional amplifier to move the electromagnet, and the armature shifts to drive the valve core of the reversing valve to overcome the spring force, so as to transform the control signal into the valve core displacement.

The voltage and current relationship of the energized coil on the electromagnet is:

$$
u_{0}=L \frac{d_{i}}{d_{t}}+R_{0} i+K_{A} \frac{d x_{s}}{d_{t}}
$$

Taking the Laplace transform of Equation (1), we obtain:

$$
U_{0}(s)=L s I(s)+R_{0} I(s)+K_{A} s X_{s}(s)
$$


$L$-coil inductance;

$R_{0}$-internal resistance of energized coil;

$K_{A}$-back emf coefficient;

$X_{s}$-armature shift;

$U_{0}$-voltage of electromagnet;

I-input current of electro-hydraulic proportional valve.

The force $F_{B}$ exerted by the electromagnet on the valve core is related to the current $i$ and the armature displacement:

$$
F_{B}=K_{B} i-K_{C} x_{s}
$$

$F_{B}$-force applied to the spool by the electromagnet;

$K_{B}$ - conversion coefficient between current and electromagnetic force;

$K_{C}$-conversion coefficient between armature displacement and electromagnetic force.

The spool is subjected to the electromagnetic force $F_{B}$ of the electromagnet, steady-state fluid power $F_{C}=K_{F} P x_{s}$, spring force and damping force, etc. When the spool is in the balance of force, the balance equation is:

$$
F_{B}=m_{1} \frac{d^{2} x_{s}}{d t^{2}}+c \frac{d x_{s}}{d t}+K_{E} x_{s}+K_{F} P x_{s}
$$

$m_{1}$-armature weight, $\mathrm{kg}$;

$c$-damping coefficient;

$K_{E}$ - spring stiffness, $\mathrm{N} / \mathrm{m}$;

$K_{F}$-throttle orifice area gradient coefficient, $\mathrm{N} / \mathrm{m}$;

$P$ - port pressure, Pa.

Since the transient fluid force is small and negligible, Equation (4) can be simplified as:

$$
F_{B}=m_{1} \frac{d^{2} x_{s}}{d t^{2}}+c \frac{d x_{s}}{d t}+K_{E} x_{s}
$$

Substituting Equation (3) into Equation (5) and performing the Laplace transformation, we obtain:

$$
X_{s}(s)=\frac{K_{B} I(s)}{m_{1} s^{2}+c s+K_{E}+K_{C}}
$$

Substituting Equation (2) into Equation (6), the transfer function $G_{A}(s)$ of the electrohydraulic proportional valve can be obtained:

$$
G_{A}(s)=\frac{X_{s}(s)}{U_{0}(s)}=\frac{K_{B}}{\left[\left(L s+R_{0}\right)\left(m_{1} s^{2}+c s+K_{E}+K_{C}\right)+K_{A} s\right]}
$$

Additionally, the transfer function between the spool displacement of the electrohydraulic proportional valve and the input current of the electromagnetic coil is:

$$
G_{Z}(s)=\frac{X_{s}(s)}{I(s)}=\frac{K_{B}}{m_{1} s^{2}+c s+K_{E}+K_{C}}
$$

Due to the small output voltage of the controller, the electro-hydraulic proportional valve cannot be directly controlled. The proportional amplifier needs to convert the smaller voltage into a larger current to control the proportional valve:

$$
G_{T}(s)=\frac{I(s)}{U(s)}=K_{T}
$$

$U$-voltage output by the controller, $\mathrm{V}$;

$K_{T}$-proportional gain, $\mathrm{A} / \mathrm{V}$. 
Aiming at the four-way valve control double rod hydraulic cylinder, a high-order differential equation mathematical model is established to analyze the flow continuity equation of the hydraulic cylinder. The flow into the hydraulic cylinder can be expressed as:

$$
Q_{1}=A \frac{d y}{d t}+\frac{V_{1}}{\beta} \frac{d P_{1}}{d t}+C_{i p}\left(P_{1}-P_{2}\right)+C_{o p} P_{1}
$$

$A$ - piston effective area;

$y$-piston displacement;

$\beta$-effective elastic modulus of oil, generally $7000 \mathrm{~kg} f / \mathrm{cm}^{2}$;

$C_{i p}$-cylinder leakage coefficient;

$\mathrm{C}_{o p}$ - external leakage coefficient of cylinder;

$V_{1}$-total volume of inlet side high pressure chamber;

$P_{1}$-hydraulic cylinder working chamber oil pressure;

$P_{2}$-hydraulic cylinder return oil chamber oil pressure.

The oil return flow of the hydraulic cylinder is:

$$
Q_{2}=A \frac{d y}{d t}+\frac{V_{2}}{\beta} \frac{d P_{2}}{d t}+C_{i p}\left(P_{1}-P_{2}\right)+C_{o p} P_{2}
$$

In the formula, $V_{2}$ is the total volume of oil return side.

Then, we define:

$$
Q_{f}=\frac{Q_{1}+Q_{2}}{2}=A \frac{d y}{d t}+\frac{1}{2 \beta}\left(V_{1} \frac{d P_{1}}{d t}-V_{2} \frac{d P_{2}}{d t}\right)+C_{i p}\left(P_{1}-P_{2}\right)+\frac{C_{o p}}{2}\left(P_{1}-P_{2}\right)
$$

Because $P_{1}=\frac{P_{s}+P_{f}}{2}, P_{2}=\frac{P_{s}-P_{f}}{2}$, among them, $P_{S}$ is oil source pressure, $P_{f}$ is load pressure, so $\frac{d P_{1}}{d t}=\frac{1}{2} \frac{d P_{f}}{d t}=-\frac{d P_{2}}{d t}$, and we have:

$$
V_{1} \frac{d P_{1}}{d t}-V_{2} \frac{d P_{2}}{d t}=\frac{V_{1}+V_{2}}{2} \frac{d P_{f}}{d t}=A \frac{d y}{d t}
$$

Among them, $V=V_{1}+V_{2}$ represents the total volume of inlet and inlet oil sides. Let the total leakage coefficient be $C_{1}=C_{i p}+\frac{C_{o p}}{2}$; therefore, the flow continuity equation can be obtained as follows:

$$
Q_{f}=A \frac{d y}{d t}+\frac{V}{4 \beta} \frac{d P_{f}}{d t}+C_{1} P_{f}
$$

\subsection{Simulation Test Analysis}

As the hydraulic system of the combine harvester is complex and has many actuator parts, in order to determine the position of the monitoring points more accurately, a simulation model of a combine harvester multi-sensor hydraulic system is built based on statistical data, as shown in Figure 1.

According to the operating conditions of the combine harvester, we set the simulation parameters of the main components, as shown in Table 1, and added a step signal to simulate the operating conditions of the sudden increase in the load of the combine harvester for simulation analysis. The simulation signal is shown in Figure 2. According to the simulation results, the best position of the monitoring point was determined. 


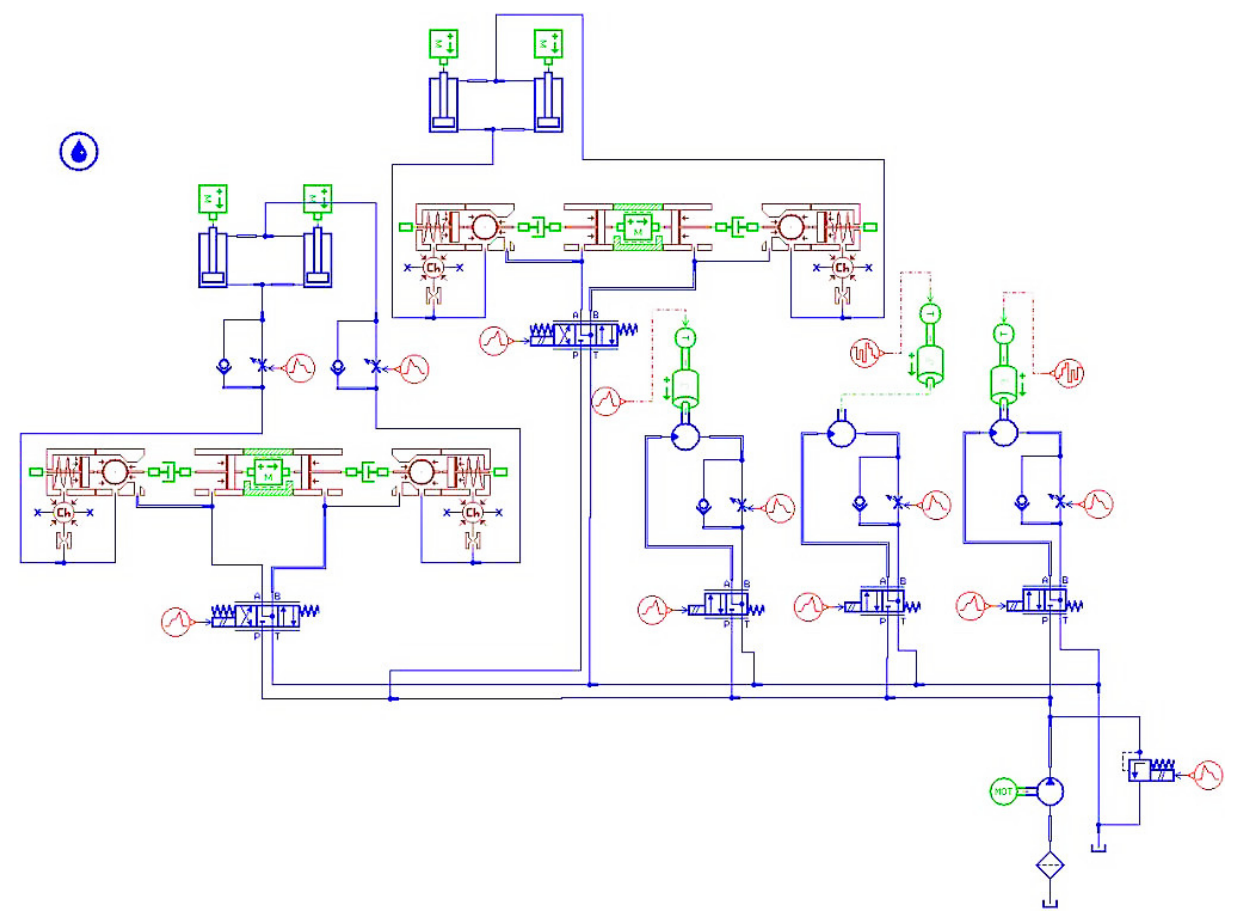

Figure 1. Hydraulic system simulation model of a combine harvester.

Table 1. Main component simulation parameters.

\begin{tabular}{cc}
\hline Name & Value \\
\hline Pump delivery $(\mathrm{mL} / \mathrm{r})$ & 175 \\
Rated speed of pump $(\mathrm{r} / \mathrm{min})$ & 2500 \\
System pressure $(\mathrm{MPa})$ & 20 \\
Diameter of cylinder of cutting table $(\mathrm{mm})$ & 150 \\
Cylinder piston rod diameter $(\mathrm{mm})$ & 40 \\
Oil cylinder load $(\mathrm{Kg})$ & 400 \\
Diameter of cylinder of rotary wheel $(\mathrm{mm})$ & 80 \\
Cylinder piston rod diameter $(\mathrm{mm})$ & 30 \\
Oil cylinder load $(\mathrm{Kg})$ & 100 \\
Motor displacement of threshing drum $(\mathrm{mL} / \mathrm{r})$ & 55 \\
Displacement of rotary wheel motor $(\mathrm{mL} / \mathrm{r})$ & 35 \\
Motor displacement of screw conveyor $(\mathrm{mL} / \mathrm{r})$ & 20 \\
\hline
\end{tabular}

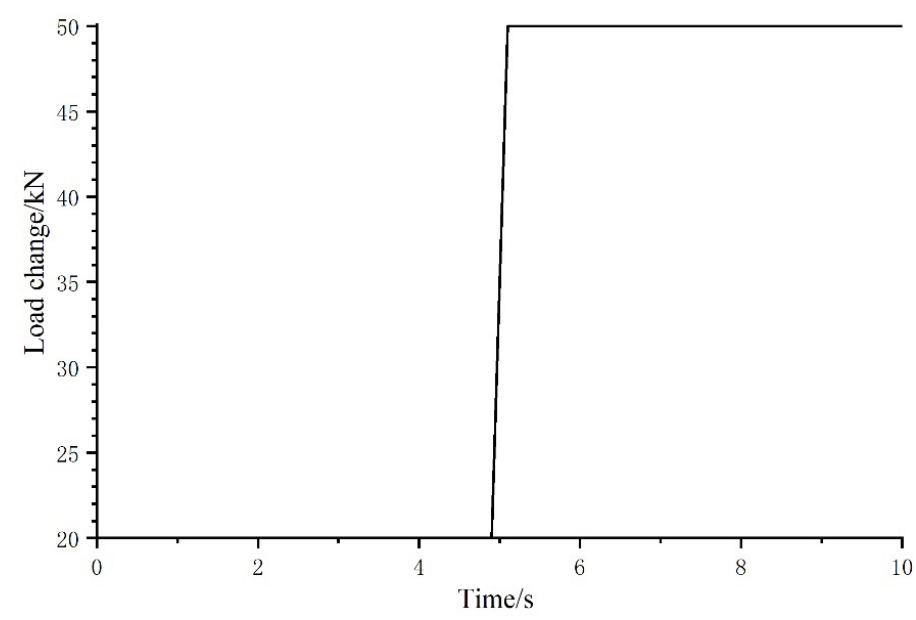

Figure 2. Load analog signal. 
Through the analysis of the simulation test, the variation in the drum speed, the drum torque and the piston displacement of the lifting hydraulic cylinder of the cutting table were obtained, as shown in Figure 3. When the load analog signal remains unchanged in the first stage, the speed of threshing drum is relatively stable at about $800 \mathrm{r} / \mathrm{min}$. The torque of the threshing drum is about $520 \mathrm{~N} \cdot \mathrm{m}$, which is in a relatively stable state. The cutting table takes $2 \mathrm{~s}$ to adjust to a suitable height, and then remains unchanged.

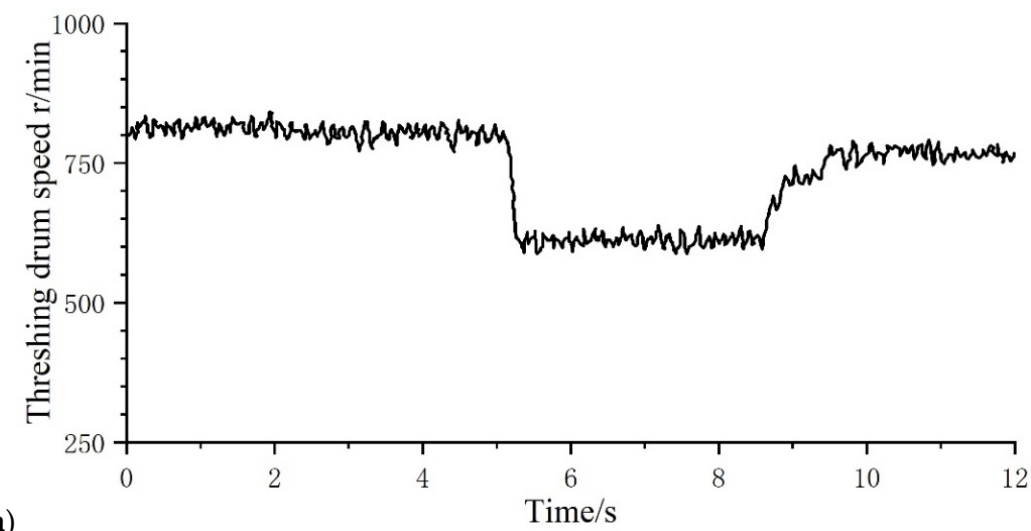

(a)

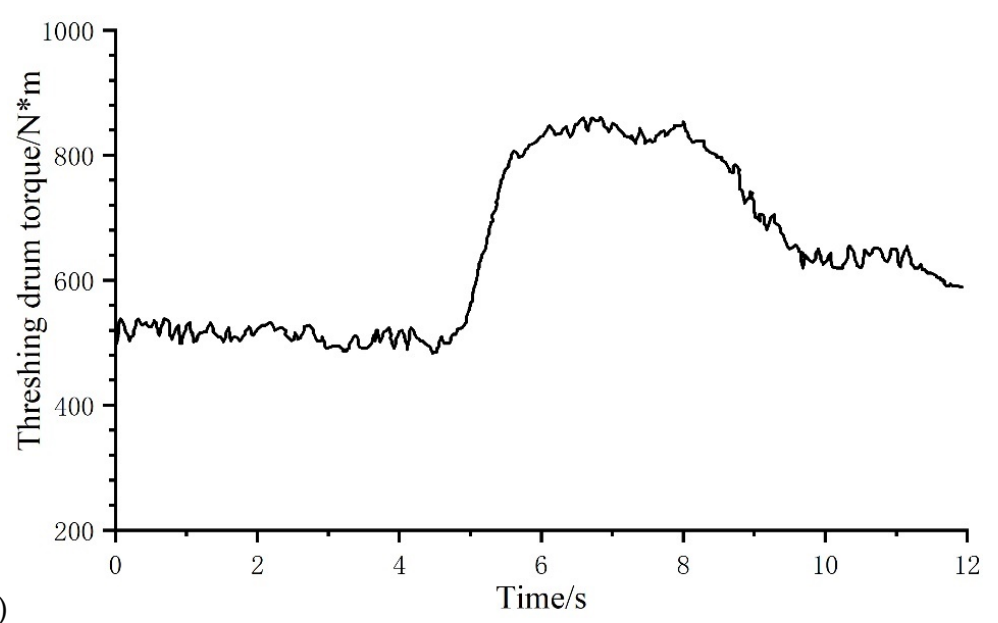

(b)

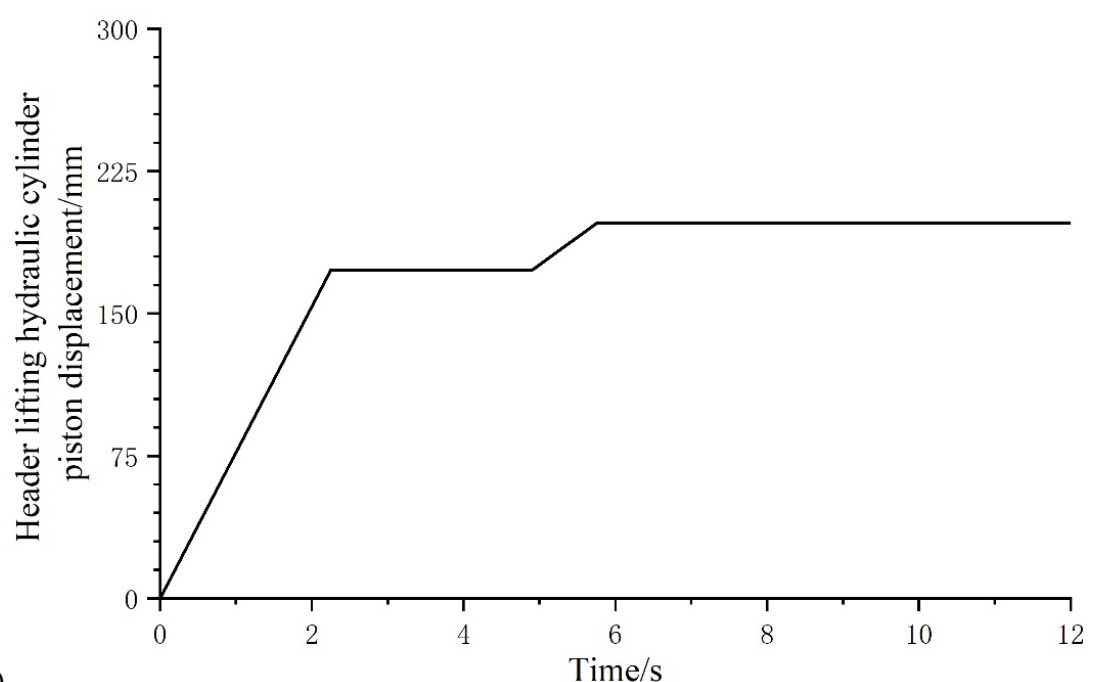

(c)

Figure 3. Output signals of simulation analysis: (a) change in speed of threshing drum, (b) change in torque of threshing drum, (c) height variation diagram of cutting table. 
When the load suddenly increased, the threshing cylinder rotation speed instantly fell to $600 \mathrm{r} / \mathrm{min}$. The torque increased with a time of close to $1 \mathrm{~s}$ to about $840 \mathrm{~N} \cdot \mathrm{m}$. The cutting machine, to prevent the crops being stranded in the subsequent process, was adjusted to a suitable height to prevent issues such as congestion. In order to reduce crop feeding, we reduced the load of the rotating parts of the harvester. The load signal was kept at a constant value after a sudden increase, and the height of the cutting table remained unchanged after a short adjustment, but the speed and torque of the threshing drum recovered to the basic stable state after $4 \mathrm{~s}$.

By analyzing the simulation results, it can be seen that the change in load has a great impact on the rotating parts of the harvester, which easily impacts the hydraulic components and causes failures, and has a small impact on the height of the cutting table. However, adjusting the height of the cutting table is an effective method to control the amount of crop feeding, so it cannot be ignored. Therefore, it is necessary to install sensors on the threshing drum, screw conveyor, wheel and other key rotating parts and cutting table for real-time monitoring [21,22].

\subsection{Design of On-Line Monitoring System}

Based on the above analysis; the establishment of a combine harvester cutting machine, transmission channel, cylinder and other key parts of the main torque model; using the theory of multiple sensor fusion and data mining methods [23,24]; using a torque sensor, displacement sensor, speed sensor and strain sensing device; choosing the appropriate hardware and software; and the research and development of new analysis module, an on-line monitoring system for the hydraulic actuator of a harvester is designed. The overall design scheme of the hydraulic monitoring system of a combine harvester is shown in Figure 4. Under realistic conditions, the following assumptions should be made when testing the on-line monitoring system: 1 . No rain and snow; 2 . The wind force shall not be higher than grade IV; 3 . The air humidity is less than $60 \%$; 4 . Soil humidity is less than $70 \%$; 5. The plant density is less than 3600 plants/mu.

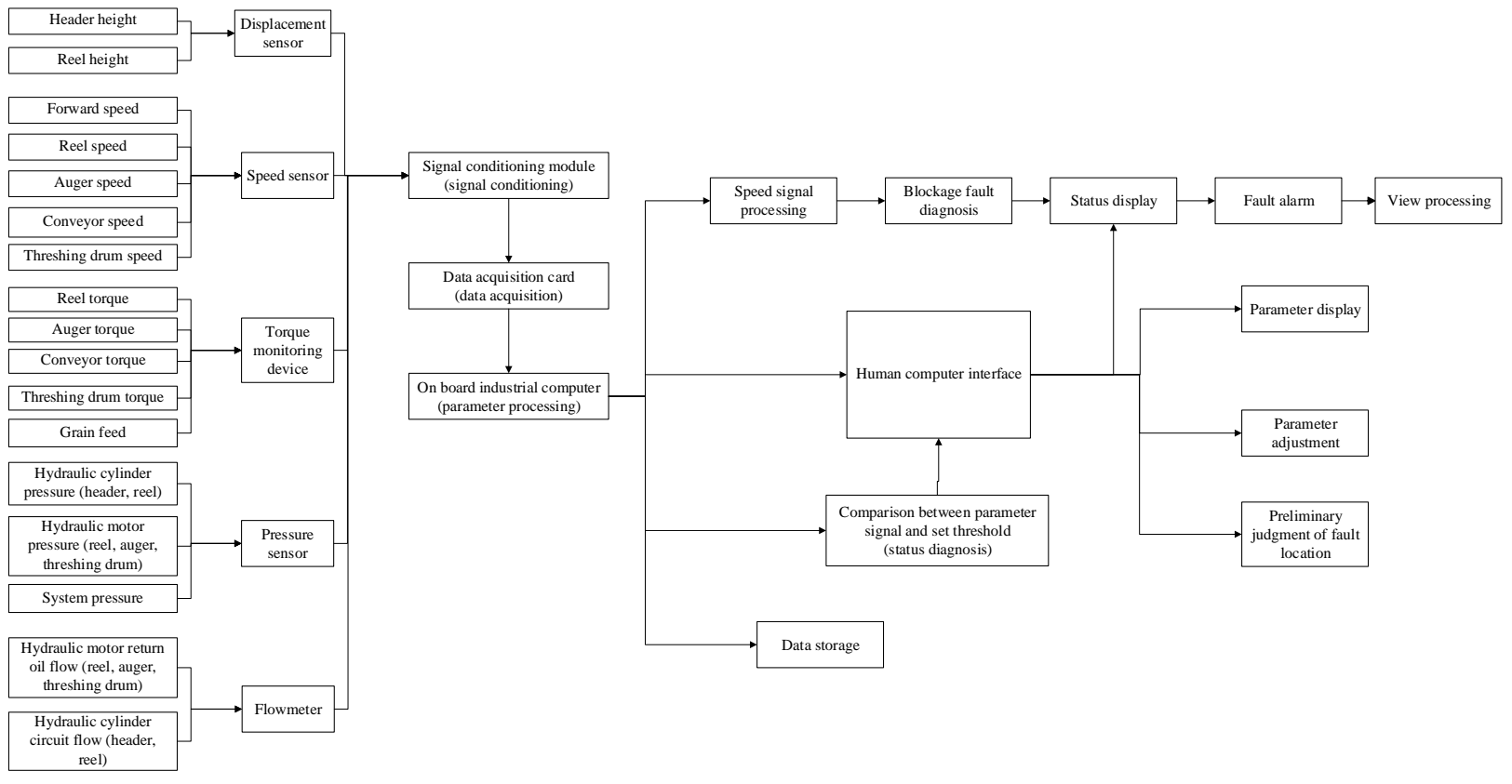

Figure 4. The overall design of hydraulic monitoring system for a combine harvester.

\subsubsection{Design of Monitoring Points and Monitoring Parameters}

Based on the simulation test analysis of the hydraulic system of the combine harvester, flow sensors and pressure sensors are installed at the corresponding positions of the main 
oil circuit and branch oil circuit of the hydraulic system of the whole machine, and strainsensing devices such as displacement sensors and torque sensors are installed at the key working parts of the combine harvester [25]. The monitoring points of the hydraulic system are shown in Figure 5.

Each sensor collects and monitors the working state of the combine hydraulic system and executive components. The collected data are processed and transmitted to the industrial computer, and the detected flow, pressure, displacement and other related parameter information are displayed on the display screen. The working condition of the combine hydraulic executive components is judged according to the interface display, and the fault judgment is realized at the same time.

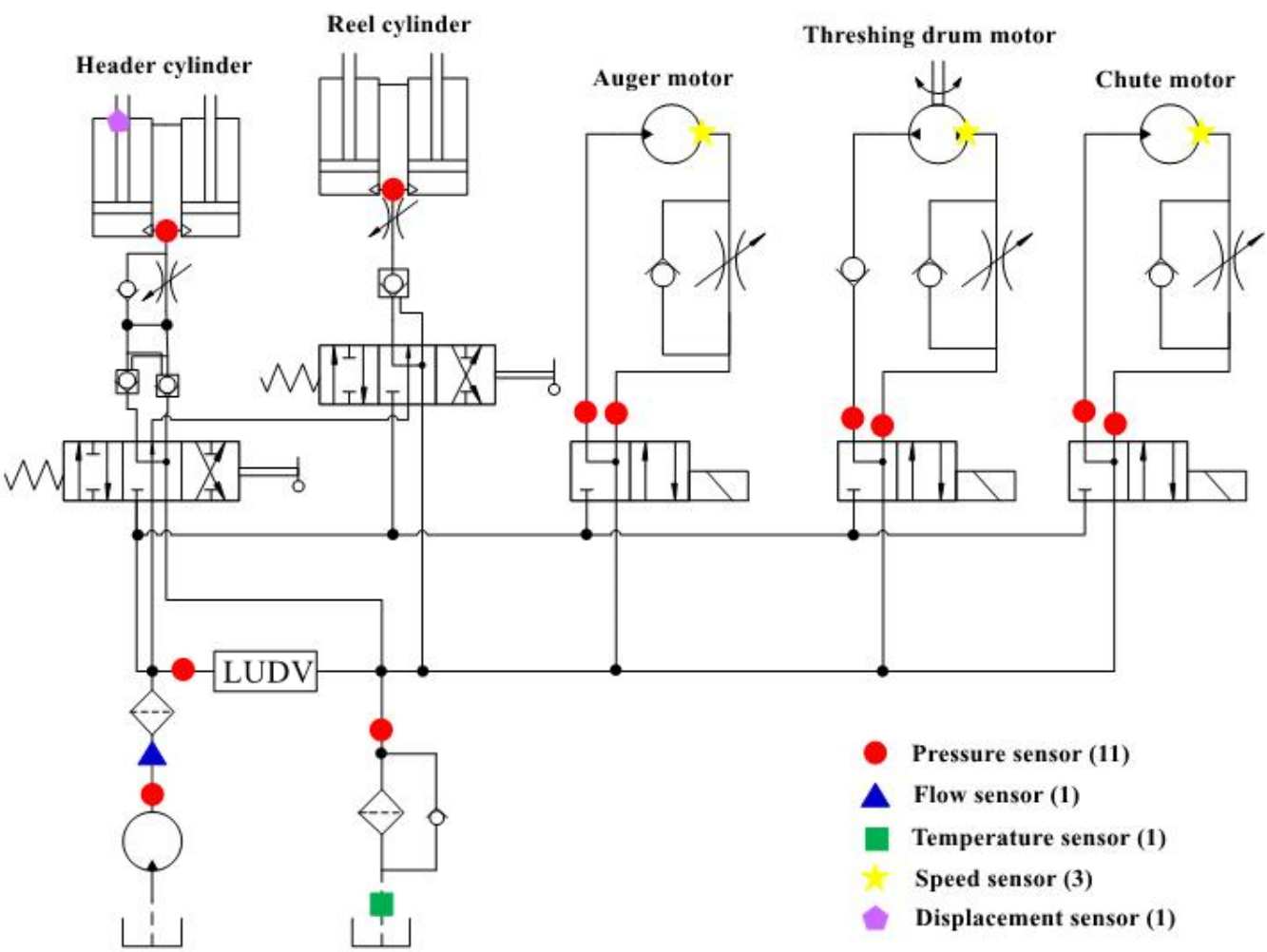

Figure 5. Hydraulic system monitoring point bitmap.

The pressure sensor is mainly installed in the hydraulic oil circuit of the oil cylinder and motor. In order to reduce the impact of the sensor on the flow channel, it is connected to the oil channel by full flow installation. Finally, the system is debugged to make the system pressure less than $30 \mathrm{MPa}$ to meet the requirements of the monitoring system. The flow sensor adopts a threaded connection and is installed at the oil inlet of the system. The temperature sensor adopts a threaded connection, and the installation position is the system oil return port. The commissioning system makes the oil temperature measurement range $10-200{ }^{\circ} \mathrm{C}$, meeting the requirements of the monitoring system. The speed sensor is mainly installed at the reel motor and threshing drum motor, which are connected by thread. The commissioning system finally meets the requirements of a speed measurement range of 0-3600 r/ min. The displacement sensor is connected to the piston rod of the header oil cylinder through thread. It is important to pay attention to neutrality during installation. The commissioning system finally meets the requirements of $0-500 \mathrm{~mm}$ for the static settlement monitoring of the header.

Through multiple sensors set on the hydraulic circuit, the lifting speed and static settlement of the header and reel, hydraulic motor speed, oil temperature and oil pressure of the hydraulic system of the whole machine can be displayed in real time, and the 
operation on-line monitoring of the hydraulic actuator of the combine can be accurately carried out.

\subsubsection{Software Design of On-Line Monitoring System}

LabVIEW is a development environment based on graphical programming language. As a standard instrument control and data acquisition software, LabVIEW has been widely used in the field of measurement and testing [26-28]. LabVIEW software uses "VI" as the abbreviation for the graphical program, and each program includes a "front panel" for similar instrument regulation and control and a "program block diagram" for similar internal processing connection lines. When you click the "new VI" menu on the startup screen, you can create a blank program, namely VI. When you click the "open" menu, you can browse and open an existing VI. After entering the VI interface with the new or open menu, you can open two windows at the same time: "front panel" and "program block diagram". The front panel is the interface between VI code and instrument users, that is, the virtual instrument panel of VI. There are two types of objects on this interface: user input and display output. Right clicking on the front panel window calls out the control palette, which contains all the objects that can be used when creating the front panel. The program block diagram contains the program code represented graphically. The user programs, controls and processes the VI in the program block diagram, and the input and output controls are defined on the front panel. Right clicking the program block diagram window calls the function palette, which contains all the objects that can be used when creating the program block diagram. In addition, the tool palette can be called to create, modify and debug VI programs, whether on the front panel or in the program block diagram.

LabVIEW 2016 software (American National Instrument, Austin, TX, USA) can be used to program and design the on-line monitoring system for the hydraulic actuator parts of a combine harvester. The system continuously monitors the measurement data transmitted on the CAN bus network, reads the visa configuration serial port data, analyzes and processes the data, displays and saves the working condition parameters of each hydraulic actuator of the combine in real time with the interface, and performs fault logic judgment. Once a fault occurs, the system will immediately give an alarm signal. The software runs directly on the on-board computer, which is convenient for the driver to harvest and deal with the fault conditions in time.

The software design of the on-line monitoring system is mainly composed of a landing interface design, front panel design, program design, program debugging and operation, and the overall framework is shown in Figure 6. The monitoring system follows the following ideas: when the combine is started, the monitoring system first performs selfinspection, and gives an alarm if there is a fault in the combine; when no fault is detected, the data acquisition card is driven to analyze and process the data collected by the sensor, and finally stores the data, which is convenient for the driver to view and call in real time. When the system operates normally, the interface displays the working status of each monitoring point. When the hydraulic components operate abnormally, the system prompts a fault alarm. 


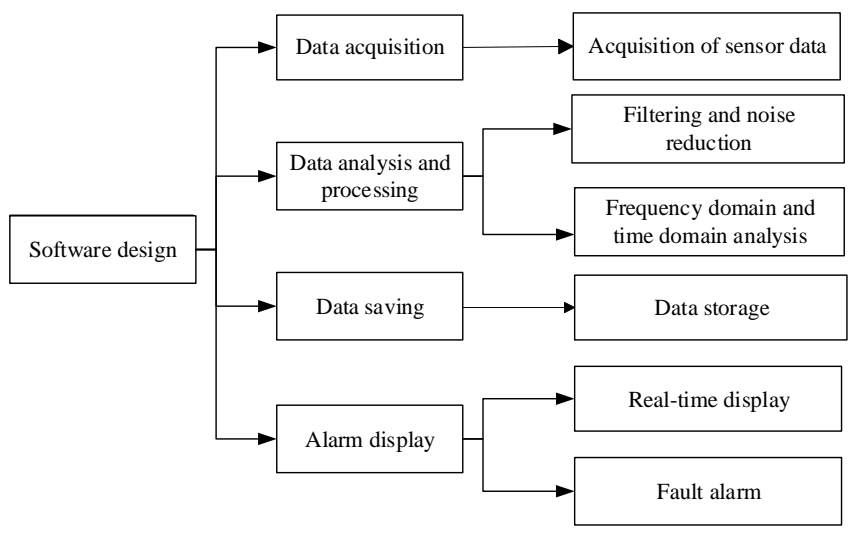

Figure 6. Overall architecture of software design.

In order to prevent non operators from entering the system and to protect the security of the system information, it is necessary to design a login interface. Only the operators in the database set in the program block diagram can login the system for relevant operations. The login interface and operation authority setting are realized by LabVIEW programming. The main program block diagram of the login interface is shown in Figure 7.

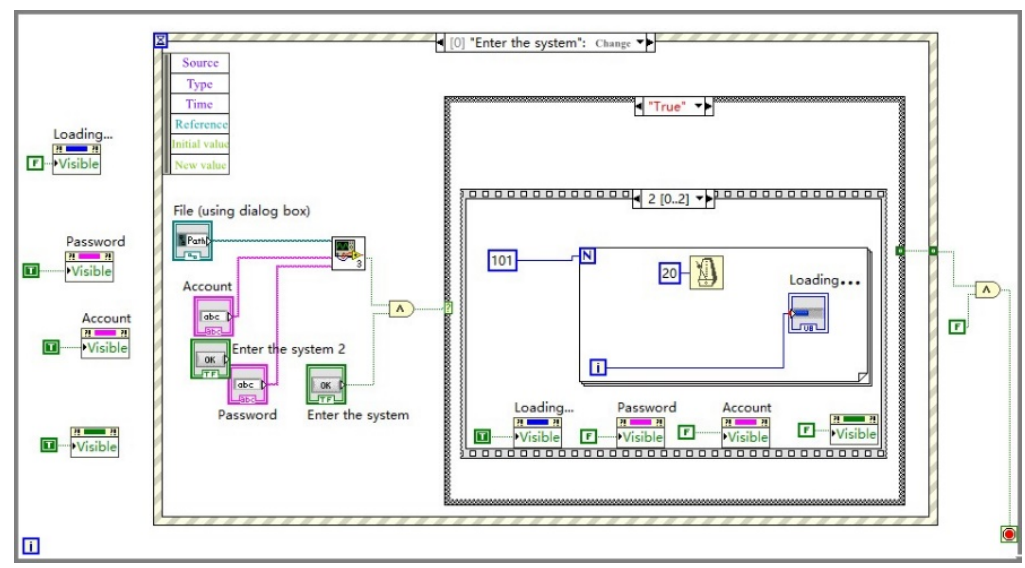

Figure 7. Main program block diagram of the login interface.

Using the method of modular design, the display interface of the monitoring system adopts the while loop structure. When there is no timeout part in the event structure, it always waits for the occurrence of the event structure. This structure can effectively reduce the utilization of CPU. When the event structure value changes, the display system triggers the corresponding event. If the value of "threshing drum" in the display interface changes (or triggered by the mouse), the working mode selection interface of the pressure monitoring system can be entered. The main display interface of the system is shown in Figure 8, which can be used for parameter adjustment, executive component monitoring, waveform monitoring, hydraulic system pressure and flow monitoring, historical data queries, etc. The speed acquisition program block diagram is shown in Figure 9, and the torque acquisition program block diagram is shown in Figure 10. 


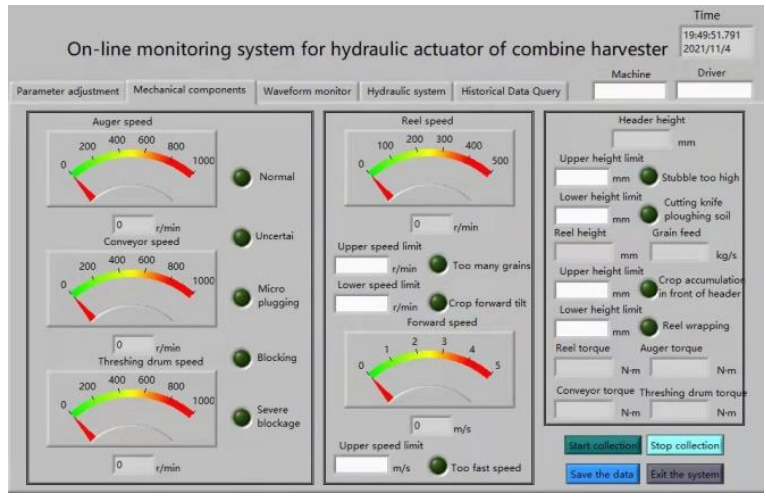

Figure 8. System main display interface.

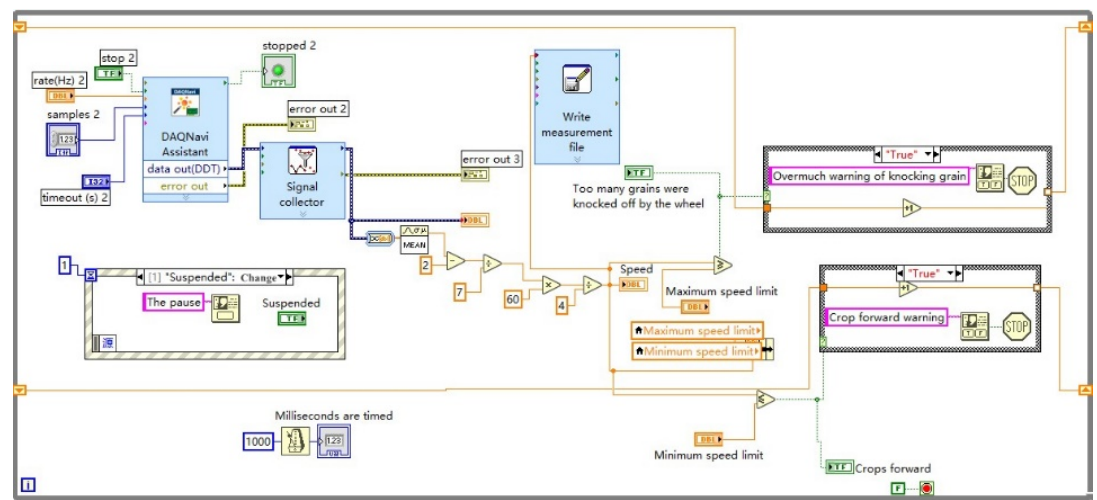

Figure 9. Speed acquisition program block diagram.

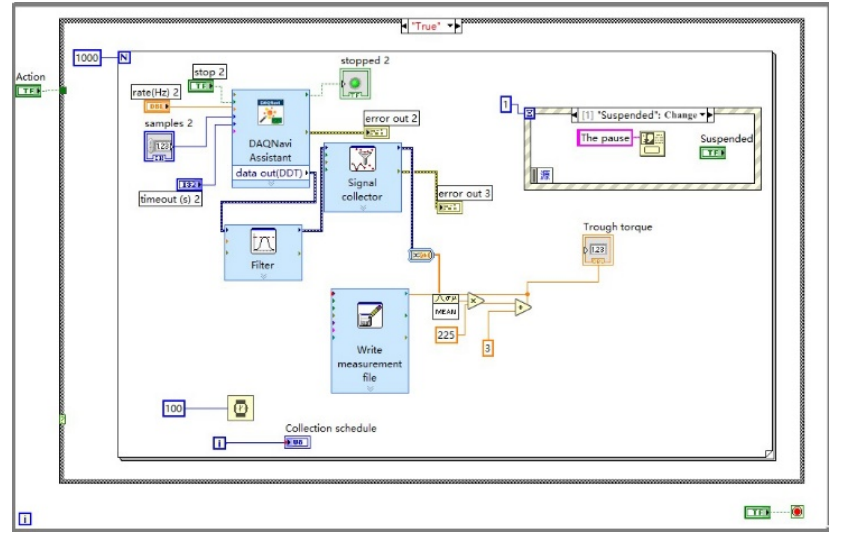

Figure 10. Torque acquisition program block diagram.

The data collected by each sensor device are transmitted to the CAN bus network in real time. The system reads the measurement data through the visa-configured serial port, analyzes and processes the data, and then displays and executes fault judgment in real time on the interface. Once a fault occurs, the system will send an alarm signal immediately. In addition, all data are saved by the system.

\subsection{Fault Judgment and Alarm Program Design}

Based on the energy distribution and time domain characteristics of IMF, the eigenvector analysis is constructed, and the support vector machine is used for fault diagnosis of the harvester hydraulic system [29]: firstly, the real-time monitoring signal of the hydraulic system is analyzed by Hilbert transform and Butterworth filter spectrum, its eigenvector 
is calculated, and then the vector machine is designed according to the control scheme diagram and control flow chart. The system fault status is classified and identified. The fault states are classified according to the four adjustment modes of normal state, hydraulic circuit pressure adjustment, threshing drum speed adjustment and other adjustment, four classifiers SVM0, SVM1, SVM2 and SVM3 are established, and the normalization mode of each two classifiers is set as [0,1], where 1 indicates corresponding fault and 0 indicates other fault states. Table 2 shows the sample identification methods of four types of adjustment classifiers.

Table 2. Sample identification method of four kinds of adjustment classifiers.

\begin{tabular}{ccccc}
\hline Fault Category & SVM0 & SVM1 & SVM2 & SVM3 \\
\hline SVM0 & 1 & 0 & 0 & 0 \\
SVM1 & 0 & 1 & 0 & 0 \\
SVM2 & 0 & 0 & 1 & 0 \\
SVM3 & 0 & 0 & 0 & 1 \\
\hline
\end{tabular}

In the judgment alarm program, the upper limit value for 6-channel pressure signals and the lower limit value for 3-channel speed signals are set, such as for the threshing drum. The filtered real-time acquisition signal is transmitted to the fault identification program through the communication connection module, and the system fault status is classified and identified through the for cycle. If it exceeds the limit, the corresponding LED alarm light flashes to remind the driver of the occurrence of fault conditions.

Through the on-line monitoring system, the harvester user can conveniently and quickly monitor the parameters of the hydraulic system and the parameters of the hydraulic actuator in real time, and analyze them through the waveform diagram, so as to adjust the parameters according to the current working conditions. It can also find and deal with operation faults in time, so as to improve the operation efficiency of the combine and greatly reduce human labor. In addition, the system also has the function of historical information query. After a fault occurs, the historical data can be retrieved for analysis to prevent the same fault from happening again.

\subsection{Experiment}

In September 2020, taking the Lovol GN60 combine (Lovol Heavy Industry Co., Ltd., Weifang, China) as the test prototype, the harvest operation test was carried out in the test field to test the performance of the on-line monitoring system of the hydraulic actuator of the combine. The installation positions of some sensors are shown in Figure 11. During the test, the temperature was $23{ }^{\circ} \mathrm{C}$, the humidity was $16 \%$, the wind direction was southeast, and the wind force was grade 2 ; the crops grew evenly and well. The system was started first, and the rated parameters were set at the on-board terminal as follows: the speed of the header auger was $145 \mathrm{r} / \mathrm{min}$, the speed of the header screw conveyor was $200 \mathrm{r} / \mathrm{min}$, the speed of the conveyor tank was $400 \mathrm{r} / \mathrm{min}$, the speed of the threshing drum was $920 \mathrm{r} / \mathrm{min}$, and the forward speed was $2 \mathrm{~m} / \mathrm{s}$. After gradually increasing each rotating part to the set rated speed, the power pedal was kept unchanged and the power of each rotating part unchanged according to the harvesting operation process; then, the forward speed was increased from 0 to $2 \mathrm{~m} / \mathrm{s}$ and this speed maintained for harvesting operation. The parameter changes of the main working parts were observed, and we found that with the increase in feeding amount, the torque of the header auger, conveying chute and threshing drum increased gradually from the initial value of 0 , and their respective rotating speeds slightly decreased, but still maintained the best operation state. When the equivalence of pressure, temperature, torque and speed exceeds the set reasonable range, the corresponding alarm indicator on the system interface lights up red to prompt the driver to deal with it in time. 


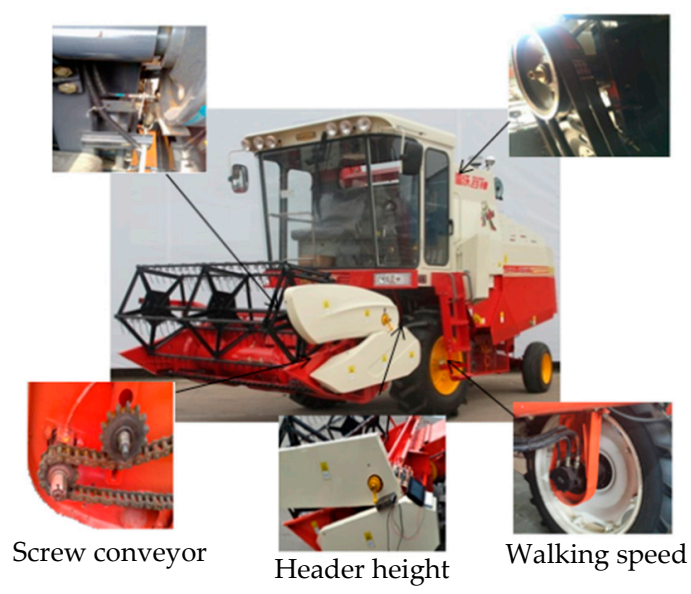

Figure 11. Part of the sensor installation location drawing.

\section{Results}

3.1. Experimental Results of Working Condition Parameters

According to the test data, the relationship curve between walking speed and the time of the combine is obtained, as shown in Figure 12. The relationship curve between rotational speed and the time of the threshing drum, conveying chute and header auger is shown in Figure 13. The relationship curve between torque and the time of the threshing drum, conveying chute and header auger is shown in Figure 14.

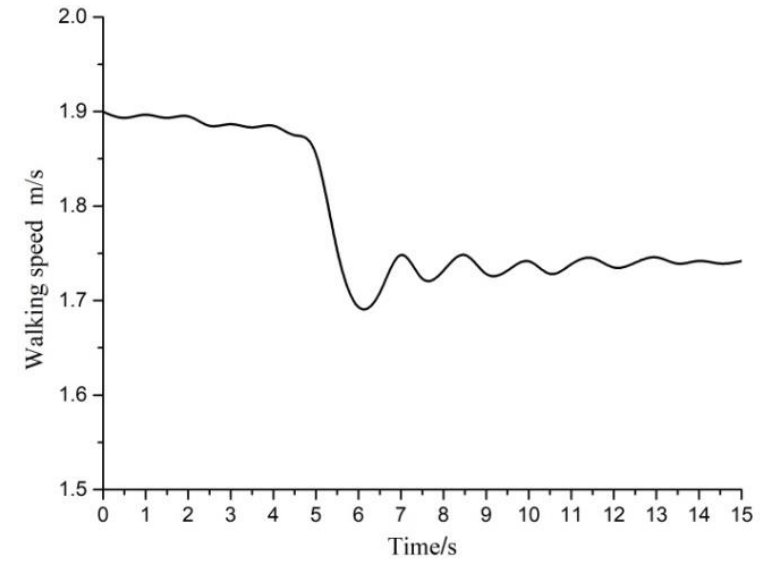

Figure 12. The relationship curve of walking speed and time. 


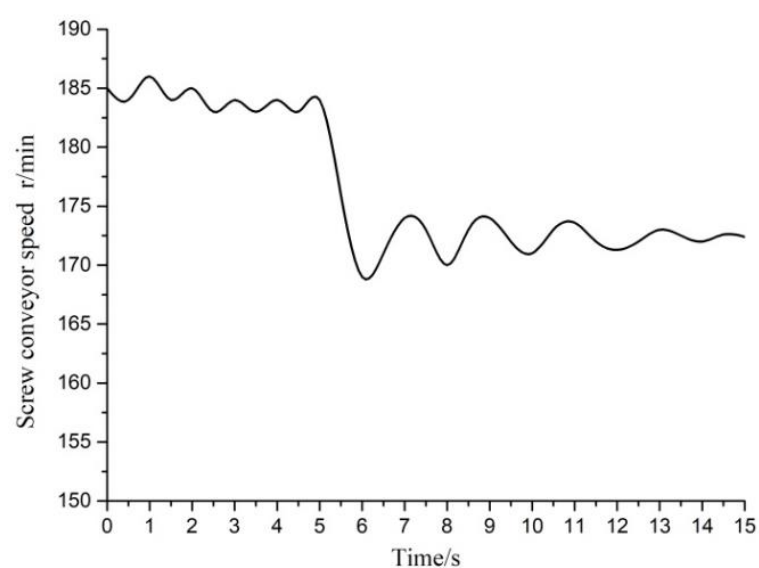

(a)

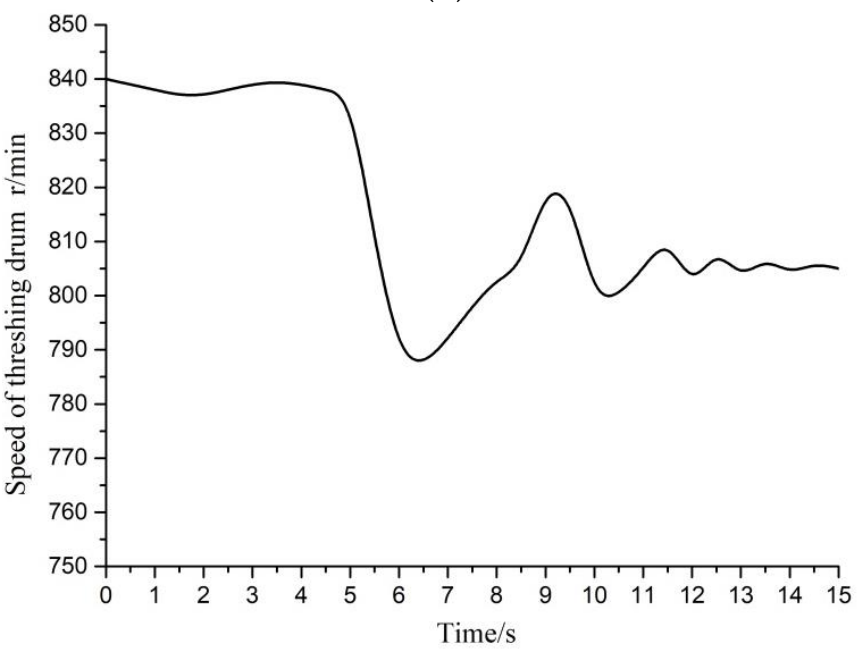

(c)

Figure 13. The relationship curve of rotation speed and time of the threshing drum, conveying trough and cutting table screw conveyer. (a) Speed of auger, (b) speed of conveyor, (c) speed of threshing drum.

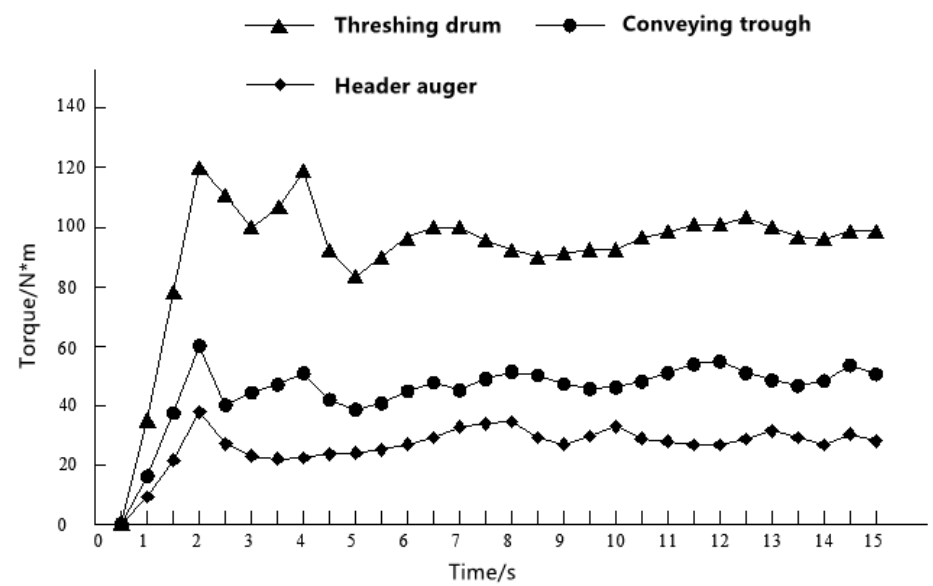

Figure 14. The relationship curve of torque and time of the threshing drum, conveying trough and cutting table screw conveyer.

\subsection{Experimental Results of Fault Diagnosis}

Under natural circumstances, the failure during harvesting operation is unpredictable and occurs a few times. Therefore, the failure conditions are artificially set during the test 
to identify the specific failure phenomena, so as to verify the accuracy of the fault alarm. The fault settings are shown in Table 3, in which the threshing drum fault test is repeated 200 times, and the screw conveyor and conveyor tank fault test are repeated 100 times, respectively. The fault alarm of the combine is shown in Table 4. The alarm error includes two situations: one is an operation fault for which the on-line monitoring system does not alarm, and the other is that the fault part of the alarm is not the actual operation fault part.

Table 3. Fault settings.

\begin{tabular}{|c|c|c|}
\hline Fault Location & Artificially Set Fault & Fault Phenomenon \\
\hline Header auger & $\begin{array}{l}\text { Reduce header height and } \\
\text { increase travel speed }\end{array}$ & $\begin{array}{c}\text { The rotating speed decreases and } \\
\text { the straw accumulates }\end{array}$ \\
\hline Conveying trough & Adjust the drive belt tensioner & $\begin{array}{c}\text { The speed decreases and the feed } \\
\text { auger is blocked }\end{array}$ \\
\hline Threshing drum & $\begin{array}{l}\text { Moderate throttle operation of } \\
\text { the engine to increase the } \\
\text { forward speed }\end{array}$ & $\begin{array}{l}\text { The speed slows down and the } \\
\text { belt rubs violently with the pulley }\end{array}$ \\
\hline
\end{tabular}

Table 4. Combine harvester failure alarm situation.

\begin{tabular}{ccccc}
\hline Job Failure & $\begin{array}{c}\text { Number of } \\
\text { Tests }\end{array}$ & $\begin{array}{c}\text { Correct Number } \\
\text { of Alarms }\end{array}$ & $\begin{array}{c}\text { Number of } \\
\text { Alarm Errors }\end{array}$ & $\begin{array}{c}\text { Alarm } \\
\text { Accuracy }\end{array}$ \\
\hline Auger blocked & 100 & 93 & 7 & $93 \%$ \\
Conveyor chute blocked & 100 & 97 & 3 & $97 \%$ \\
Threshing drum blocked & 200 & 199 & 1 & $99.5 \%$ \\
\hline
\end{tabular}

\section{Discussion of Experimental Results}

It can be observed from Figures 12 and 13 that the traveling speed of the combine decreases from $4 \mathrm{~s}$ to the lowest value of $1.69 \mathrm{~m} / \mathrm{s}$ at $6 \mathrm{~s}$. The rotating speed of the threshing drum decreased from $5 \mathrm{~s}$ to the lowest value of $788 \mathrm{r} / \mathrm{min}$ at $6.5 \mathrm{~s}$, then began to increase, and reached a relatively stable state after about $7 \mathrm{~s}$. The change trend in chute speed and header auger speed relative to time is basically the same. At $5 \mathrm{~s}$, the rotating speed of the conveying chute and the header auger began to decrease. At $6 \mathrm{~s}$, the rotating speed of the header auger also decreased to the lowest value of $168 \mathrm{r} / \mathrm{min}$. At $7 \mathrm{~s}$, the rotating speed of the conveying chute decreased to the lowest value of $341 \mathrm{r} / \mathrm{min}$. Then, both began to rise slowly and reached their relatively stable state after about $7 \mathrm{~s}$.

It can be observed from Figure 14 that the torque of the threshing drum, conveying chute and header auger increased from $0.5 \mathrm{~s}$ and reached the maximum value at $2 \mathrm{~s}$. The maximum torque of the threshing drum was $120 \mathrm{~N} \cdot \mathrm{m}$, the maximum torque of the conveying chute was $60 \mathrm{~N} \cdot \mathrm{m}$ and the maximum torque of the header auger was $38 \mathrm{~N} \cdot \mathrm{m}$. After that, the change trends in the three with time are basically the same. After about $10 \mathrm{~s}$ of fluctuation, they reached a relatively stable state. The threshing drum torque was the largest, stable at $99 \mathrm{~N} \cdot \mathrm{m}$, the conveyor tank torque was small, stable at $50 \mathrm{~N} \cdot \mathrm{m}$, and the header screw conveyor torque was the smallest, stable at $29 \mathrm{~N} \cdot \mathrm{m}$.

By analyzing the above working curve, it can be seen that in the first $4 \mathrm{~s}$, the feeding amount was small, and the forward speed decreased from the initial value of $2 \mathrm{~m} / \mathrm{s}$ to about $1.89 \mathrm{~m} / \mathrm{s}$, down by $5.5 \%$; the speed of the header auger decreased from the initial value of $200 \mathrm{r} / \mathrm{min}$ to about $185 \mathrm{r} / \mathrm{min}$, a decrease of $7.5 \%$; the rotating speed of the conveying trough decreased from the initial value of $400 \mathrm{r} / \mathrm{min}$ to about $365 \mathrm{r} / \mathrm{min}$, which decreased by $8.75 \%$; the rotating speed of threshing drum decreased from the initial value of $920 \mathrm{r} / \mathrm{min}$ to $840 \mathrm{r} / \mathrm{min}$, a decrease of $8.7 \%$. At $4 \mathrm{~s}$, the increase in feeding amount caused the traveling speed of the combine, the speed of the header auger, the speed of the conveyor trough and the speed of the threshing drum to decrease significantly, the torque of the header auger, conveyor trough and threshing drum increased, and they returned to a stable state after a period of time. The walking speed decreased to $1.75 \mathrm{~m} / \mathrm{s}, 12.5 \%$ lower than the initial 
value; the speed of the header auger decreased to $172 \mathrm{r} / \mathrm{min}, 14 \%$ lower than the initial value; the rotating speed of the conveying trough was reduced to $350 \mathrm{r} / \mathrm{min}, 12.5 \%$ lower than the initial value; and the rotating speed of threshing drum was reduced to $805 \mathrm{r} / \mathrm{min}$, $12.5 \%$ lower than the initial value.

The results are consistent with the simulation results, which shows that the designed on-line monitoring system of the hydraulic actuator of the combine can accurately monitor the working state of the combine. If the feeding amount increases too much and the speed drops below the set lower limit, the monitoring system will carry out an early fault warning. At this time, it is very easy to block, resulting in the failure of the combine. The driver should reduce the walking speed, that is, reduce the feeding amount, and increase the speed to the rated working speed after the early fault warning is completed.

The test results show that the on-line monitoring system of the hydraulic actuator of the combine operates normally, the designed and installed pressure sensor, speed sensor, temperature sensor and torque sensor have good working performance, and the functional requirements and accuracy requirements fully meet the monitoring of the field operation conditions of the combine. In addition, the alarm accuracy of the on-line monitoring system for fault conditions is $96.5 \%$, and the automatic diagnosis time of the fault alarm is less than $1 \mathrm{~min} 18 \mathrm{sec}$. Yu Changshun designed a remote fault diagnosis system for a combine harvester based on a fuzzy neural network. The prediction accuracy of the fuzzy neural network model was 88.5\% [30]. Wang Fengzhu and others developed an on-line monitoring system for peanut combine harvester operation based on a $4 \mathrm{hblz}-2$ single ridge small self-propelled peanut combine harvester. The field test showed that the accuracy of fault monitoring was $90 \%$ and the automatic diagnosis of the time of the early fault warning was $2 \mathrm{~min}$ [31]. Li Zhe designed a remote monitoring platform for a combine harvester based on B/S framework, and constructed the softmax classification model for a threshing drum blockage fault. After testing, it was found that its accuracy was 95\% [32]. Through comparison, it can be seen that the on-line monitoring system of the hydraulic actuator of the combine has higher fault alarm accuracy, a lower automatic diagnosis time and a better monitoring effect.

Using multi-sensor monitoring technology and data mining theory, the on-line monitoring system of a hydraulic actuator of a combine harvester breaks through multi-source sensor data fusion, and designs a reasonable, efficient and complete software analysis module according to the selected sensing device. Additionally, it constructs feature vector analysis based on the energy distribution and time-domain characteristics of IMF, and uses support vector machine to diagnose the fault of the harvester hydraulic system. These enrich the function of the on-line monitoring system, shorten the fault diagnosis time and improve the accuracy of fault diagnosis. The driver can understand the working condition parameters and fault status of each hydraulic actuator of the combine in real time through the on-board computer, which is convenient for timely handling, reduces the failure rate of field harvesting operation, and greatly improves the operation efficiency of the combine.

\section{Conclusions}

The on-line monitoring system of a combine harvester hydraulic actuator studied in this paper solves the shortcomings of low alarm accuracy and long fault diagnosis time of the existing monitoring system, ensures the real-time monitoring of combine harvester operation processes, quickly solves operation faults, and improves operation efficiency and quality. This study has the following advantages:

(1) By using multi-sensor monitoring technology and data mining theory, multi-source sensor data fusion is broken through, and multi-parameter real-time acquisition is realized.

(2) Based on the energy distribution and time-domain characteristics of IMF, the feature vector is constructed, and the support vector machine is used for the fault diagnosis of the harvester hydraulic system, which improves the accuracy of fault diagnosis and shortens the time of fault diagnosis. 
(3) Based on LabVIEW, a reasonable, efficient and complete software analysis module is designed to realize the real-time display and fault alarm of the main working condition parameters of the harvester.

(4) The test shows that the on-line monitoring system runs normally, and has a higher fault diagnosis accuracy and shorter automatic diagnosis time compared with other studies.

A combine harvester equipped with this monitoring system can facilitate the driver to operate more efficiently and reasonably, reduce the failure rate of field operation, greatly improve the operation efficiency, and meet people's needs for greater automation and intelligence of combine harvesters.

Author Contributions: Conceptualization, R.L. and J.X.; methodology, R.L.; software, S.Z. and Y.C.; validation, Y.C., Y.L. and X.D.; formal analysis, R.L. and J.X.; investigation, Y.L. and X.D.; resources, R.L.; data curation, Y.C.; writing-original draft preparation, Y.C.; writing-review and editing, R.L. and Y.C.; supervision, R.L.; project administration, J.X. All authors have read and agreed to the published version of the manuscript.

Funding: This work was supported in part by the Ministry of Science and Technology (key R \& D projects in the 13th five year plan, 2017YFD0700200), Department of Science and Technology of Shandong Province (major scientific and technological innovation projects, 2019TSLH0303).

Institutional Review Board Statement: Not applicable.

Informed Consent Statement: Not applicable.

Data Availability Statement: Not applicable.

Conflicts of Interest: The authors declare no conflict of interest.

\section{References}

1. Reinke, R.; Dankowicz, H.; Phelan, J. A dynamic rain flow model for a mass flow yield sensor on a combine. Precis. Agric. 2011, 12, 732-749. [CrossRef]

2. Liang, Z.; Li, Y.; Zhao, Z. Structure optimization of a grain impact piezoelectric sensor and its application for monitoring separation losses on tangential-axial combine harvesters. Sensors 2015, 15, 1496-1517. [CrossRef]

3. Deng, L.L.; Li, Y.M. Current situation and development trend of rice combine harvester in China. Res. Agric. Mech. 2001, 2, 4-6.

4. Xia, L.Q.; Liang, X.X.; Wei, L.G. Research progress of automatic monitoring system for combine harvester. Agric. Mach. 2013, 19, 141-144.

5. Dębska, A.; Bieniek, J.; Fabrykowski, E. Exploitation assessment of New Holland CX780 combine harvester. Agric. Eng. 2016, 20, 43-51. [CrossRef]

6. Lu, W.T.; Zhang, L.J.; Zhang, D.X. Research status of combine harvester monitoring system. Res. Agric. Mech. 2014, 36, 256-259.

7. Liang, X.X. Research on Automatic Monitoring System of Combine Harvester; China Academy of Agricultural Mechanization: Beijing, China, 2013.

8. Dong, Q.J.; Wang, M.; Jin, H.J. Application of on-line detection system in construction machinery. Constr. Mech. 2016, 37, 66-67.

9. Ling, Y.J.; Lu, R.F.; Liao, Y.M. Grand View of combine harvester market. Agric. Mach. Mark. 2016, 4, 30-31.

10. Chen, Q.W.; Han, Z.D.; Cui, J.W. Development status and trend analysis of self-propelled grain combine harvester. China Agric. Sci. Technol. Herald 2015, 17, 109-114.

11. Craessaerts, G.; Baerdemaeker, J.D.; Saeys, W. Fault diagnostic systems for agricultural machinery. Biosyst. Eng. 2010, 106, 26-36. [CrossRef]

12. Chen, J.; Wang, Y.F.; Wang, Y.H. Design of remote video monitoring system for combine operation. Meas. Control. Technol. 2017, $12,115-119$.

13. Ren, H.X. Application and development trend of automatic control in combine harvester. Mod. Agric. Equip. 2004, 6, 57-60.

14. Zheng, S.Y.; Chen, J.; Li, Y.M. Multisensor signal acquisition and data processing system of combine harvester. J. Agric. Mach. 2011, 63 (Suppl. S1), 107-111.

15. Yang, Y.X.; Xu, L.P.; Ren, D.Z. Design of condition detection system for excavator hydraulic system based on Virtual Instrument Technology. Mach. Tool Hydraul. 2012, 40, 133-135.

16. Zhang, H.P.; Pan, S.L. Study on working efficiency of combine harvester. Agric. Dev. Equip. 2017, 5, $132-134$.

17. Wen, H.; Yao, C.F. The fault of hydraulic system and trouble-shooting. Appl. Mech. Mater. 2014, 46, 1121-1124. [CrossRef]

18. Wang, L.T.; Zhu, S.X.; Lin, G.Z. Several new technologies of modern combine harvester. Mod. Agric. 2014, 3, 58-59.

19. Chen, J.; Wang, X.L.; Wang, Y.F. Monitoring system for main parts working condition of combine harvester based on Android mobile phone. J. Agric. Mach. 2016, 47 (Suppl. S1), 203-207. 
20. Chen, H.F.; Guo, H.; Zhang, X.J. Application status and development trend of hydrostatic technology in agricultural machinery. Xinjiang Agric. Mech. 2016, 2, 11-13.

21. Xu, K. Blockage Fault Diagnosis and Alarm System for Combine Harvester Based on BPNN and DS Theory. Master's Thesis, Jiangsu University, Zhenjiang, China, 2016.

22. Xiong, S.H. Study on the State Monitoring System of Combine Harvester. Master's Thesis, Shanghai Jiaotong University, Shanghai, China, 2018.

23. Dong, S.; Yuan, C.H.; Gu, C. Research summary of intelligent agricultural machinery control platform based on multi-disciplinary technology integration. J. Agric. Eng. 2017, 38, 1-11.

24. Hu, Y.X.; Yan, C.L. Application of data mining technology in quality control of agricultural machinery. J. Agric. Mach. 2007, 38, 153-156.

25. Gao, F. Research on Monitoring Device for Main Working Parts of Combine Harvester. Master's Thesis, Zhejiang University, Hangzhou, China, 2012.

26. Guo, S.G.; Ren, L.J.; Wang, G.Z. Virtual instrument system based on LabVIEW and PCI-1710. Instrum. Technol. Sens. 2011, 10, 35-37.

27. Yang, Y.X. Design and Research of Excavator Hydraulic System State Detection System Based on LabVIEW. Master's Thesis, Henan University of Science and Technology, Luoyang, China, 2012.

28. Nikeshin, A.V.; Shnitman, V.Z. Testing the conformance of implementations of the EAP protocol and its methods to internet specifications. Program. Comput. Softw. 2019, 45, 417-423.

29. Ying, L.; Kun, W. Study on fault diagnosis and load feedback control system of combine harvester. In Proceedings of the Seventh International Conference on Electronics and Information Engineering, Nanjing, China, 17-18 September 2016.

30. Yu, C.S. Research on Remote Fault Diagnosis System of Combine Harvester Based on Fuzzy Neural Network. Master's Thesis, Hubei University of Technology, Wuhan, China, 2019.

31. Wang, F.Z.; Zhang, J.N.; Li, R.C.; Wei, L.G.; Han, X.; Liu, Y.C. Design of on-line monitoring and fault early warning system for peanut combined harvester. J. Agric. Mach. 2015, 46 (Suppl. S1), 69-73.

32. Li, Z. Research on Remote Monitoring Platform and Fault Analysis of Combine Harvester. Master's Thesis, Hubei University of Technology, Wuhan, China, 2019. 